\title{
A Comparative Evaluation of Illicit Drug use in Patients with or Without Controlled Substance Abuse in Interventional Pain MANAGEMENT
}

Laxmaiah Manchikanti, MD, Kim S. Damron, RN, Carla D. Beyer, RN, BSN, and Vidyasagar Pampati, MSc

\begin{abstract}
The prevalence of illicit drug use by patients in a chronic pain management practice who concomitantly abuse prescription -controlled substances is not known. The purpose of this study was to determine the prevalence of illicit drug use by patients in an interventional pain management practice, based on whether or not there was evidence of simultaneous abuse of prescription drugs.

One hundred and fifty patients in an interventional pain management practice who were prescribed controlled substances for pain treatment were selected for assessment of concomitant illicit drug use by urine drug testing. Patients were divided into two groups: Group I consisted of 100 consecu-
\end{abstract}

Illicit drug use in patients without a history of controlled substance abuse may occur in $16 \%$ of patients in an interventional pain practice setting (1). The 2001 National Household Survey on Drug Abuse (2) showed that in 2001, marijuana was used by $5.4 \%$ of the population and cocaine by $0.7 \%$ of the population, whereas $1.6 \%$ of the population used pain relievers for non-medical purposes and $0.6 \%$ of the population abused tranquilizers. An estimated 15.9 million Americans aged 12 years or older $(7.1 \%$ of the population) used an illicit drug during the month immediately prior to the survey interview in 2001. The number of persons with substance dependence or abuse increased from 4.5 million $(6.5 \%$ of the population) in 2000 to 16.6 million (7.3\% of the population) in 2001 (2). In addition, between 2000 and 2001, the estimated number of persons needing treatment for an illicit drug problem increased

From Pain Management Center of Paducah, Paducah, Kentucky. Address Correspondence: Laxmaiah Manchikanti, MD, 2831 Lone Oak Road, Paducah, Kentucky 42003. E-mail: drm@apex.net Funding: No external Support was received in completion of this study tive patients without evidence of controlled substance abuse and Group II consisted of 50 consecutive patients with documented abuse of prescription controlled substances. All patients underwent urine testing with the Rapid Drug Screen ${ }^{\mathrm{TM}}$ test. The test is a onestep, lateral flow immunoassay for the simultaneous detection of four illicit drugs (i.e., amphetamine, methamphetamine, marijuana, and cocaine).

Results showed a prevalence of illicit drug abuse in patients without a history of controlled substance abuse of $14 \%$. In contrast, illicit drug abuse in patients with a history of controlled substance abuse was $34 \%$. Marijuana was the drug of choice in both groups, with $22 \%$ in the prescription abuse group and $10 \%$ in the non-abuse group. The second most commonly used illicit drug in both groups was cocaine.

This study demonstrated a clinically significant use of illicit drugs, particularly marijuana and cocaine in an interventional pain management setting, in patients with or without evidence of concomitant abuse of prescription controlled substances.

Keywords: Drug abuse, illicit drugs, licit drugs, prescription controlled substances, controlled substance agreement, opioid abuse, marijuana, cocaine, methamphetamine, Rapid Drug Screen

drugs in the past year (4). Consequently, it is expected that patients abusing controlled substances are more likely to concomitantly abuse illicit drugs.

The problem of marijuana use is complicated by recent evidence of its potential analgesic effects. Cannabinoids block pain in laboratory pain models and in some patients with cancer or non-cancer pain (5-7). Cannabinoids have been reported as effective against thermal, mechanical, and chemical pain, with a potency and efficacy comparable to opioids in models of acute pain (5). Further, cannabinoids have been shown to modulate inflammatory (6) and neuropathic pain (7). Reviews have described an endogenous cannabinoid system involved in pain modulation that produces analgesia through the same brain stem circuitry involved in opioid analgesia (the endogenous ligand anandamide) (5, 8-10). Moreover, independent of the opioid receptor, cannabinoid analgesia is produced with Tetrahydrocannabinol (THC), the major pharmaceutically active constituent of cannabis It has been postulated that co-administration of a cannabinoid may lead to a lower opioid requirement (11, 
Table 1. Illicit drug abuse in patients with or without history of prescription drug abuse

\begin{tabular}{|l|c|c|}
\hline & Group I (without controlled substance abuse) & Group II (with controlled substance abuse) \\
\hline Marijuana & $10 \%$ & $22 \%$ \\
\hline Cocaine & $4 \%$ & $12 \%$ \\
\hline Methamphetamine & $0 \%$ & $0 \%$ \\
\hline Amphetamine & $0 \%$ & $0 \%$ \\
\hline Total Abuse & $14 \%$ & $34^{\star}$ \\
\hline
\end{tabular}

* Indicates significant difference

12). A medical marijuana access program established in Canada has reported on the medical properties of marijuana (11-13).

These developments may increase the already common use of marijuana in the United States. The Drug Enforcement Administration (DEA) considers marijuana a "gateway" to the world of illicit drug use. Among the reasons marijuana use is widespread includes a relaxed public perception of potential harm, popularization by the media, and advocates of legalization. However, use of marijuana is associated with serious complications and addiction. The deleterious effects of marijuana, used in conjunction with controlled substances, are not known.

Cocaine is the second most used illicit drug in the United States. Cocaine use is associated with severe medical complications. Cocaine has been shown to increase the likelihood of accidental death when used in combination with alcohol. However, its use in combination with controlled substances is not known. There is no medical value for cocaine, other than as a local anesthetic. Other commonly used illicit drugs include amphetamines and heroin.

There are no controlled studies evaluating illicit drug use in chronic pain patients who concomitantly abuse prescription drugs. Hence, this trial was undertaken to evaluate the prevalence of illicit drug abuse in patients with or without controlled substance abuse.

\section{Methods}

In an interventional pain management practice 150 consecutive patients receiving controlled substances, including opioids, were selected for testing for illicit drug use with an office-based urine drug test. Group I consisted of 100 patients without controlled drug abuse, whereas Group II consisted of 50 patients with evidence of abuse of controlled drugs. The presence of drug abuse was determined by history, physical examination, evidence of doctor shopping, other prescription drug abuse, unauthorized escalation of dosage, and appropriate clinical response to controlled substance medications (i.e., stable doses without evidence of drug dependence). Abuse was also defined as obtaining controlled substances from other physicians or other identifiable sources and/or violation of controlled substance agreements. All patients had a prior controlled substance agreement, and gave informed consent for the drug testing. The person obtaining the consent and the person performing the testing were different. The results were blinded to the evaluating author, statistician, the patient, and other members of the study group.

All tests were performed at the practice location utilizing the Rapid Drug Screen $^{\mathrm{TM}}$ (American Biomedia Corporation, Kinderhook, New York). The test is a one-step, lateral flow immunoassay for the simultaneous detection of up to nine drugs by urine analysis. Each analysis occupies a separate channel in a test card. This is intended for use in the qualitative detection of the various drugs. Rapid Drug Screen ${ }^{\mathrm{TM}}$ is a competitive immunoassay, utilizing highly specific reactions between antibodies and antigens for the simultaneous detection of cocaine, opiates, amphetamines, cannabinoids, barbiturates, benzodiazepines, methamphetamine, phencyclidine, and tricyclic antidepressants in urine. The testing was performed to detect the four most commonly abused illicit drugs: marijuana, cocaine, methamphetamine, and amphetamine.

Data were collected using a preprinted format without patient identification. Following the collection of data, all patients who tested negative for controlled drug abuse were included in Group I. Group II consisted of all patients determined to have abused one or more prescription controlled drugs. Data were recorded in a database using Microsoft ${ }^{\circledR}$ Access ${ }^{\circledR}$. The SPSS Version 9.0 statistical package was used to generate descriptive tables. Differences in proportions were tested using the Chi-square test. Fischer's exact test was used wherever the expected value was less than five. Results were considered statistically significant if the $P$ value was less than 0.05 .

\section{RESULTS}

One hundred patients in Group I and 50 patients in Group II were evaluated. All specimens were collected and were able to be tested for the presence or absence of four illicit drugs, i.e., amphetamine, methamphetamine, marijuana, and cocaine.

Table 1 shows the prevalence of illicit drug abuse in patients with or without a history of controlled substance abuse. Fourteen percent of patients in the nonabuse group (Group I) tested positive for illicit drugs, with $10 \%$ positive for marijuana (THC) and $4 \%$ for cocaine. In contrast, in Group II a total of 34\% were positive for illicit drug use, with $22 \%$ positive for marijuana and $12 \%$ positive for cocaine. None of the patients in Group I or Group II tested positive for amphetamines or methamphetamines. There was no evidence of concomitant marijuana and cocaine use in this study. Overall abuse of illicit drugs and marijuana use was significantly higher in patients with controlled substance abuse compared to patients without controlled substance abuse $(\mathrm{P}=0.0095)$.

\section{DisCusSION}

This consecutive, double-blind, clinical evaluation showed a high prevalence of illicit drug use in patients with concomitant controlled substance abuse, with an overall prevalence of $34 \%$. Twentytwo percent of patients tested positive for marijuana and $12 \%$ for cocaine. In patients without evidence of abuse of prescription drugs, $14 \%$ tested positive for illicit drugs, with $10 \%$ positive for marijuana and $4 \%$ for cocaine. Marijuana was the 
most commonly used illicit drug in both groups. No combined use of illicit drugs was seen in either group.

Marijuana is the most widely used and readily available illicit drug in the United States, with an estimated 11.5 million current users. At least one-third of the US population has used marijuana at some time. The Drug Enforcement Administration (DEA) (14) has suggested numerous reasons that marijuana use is widespread, including a relaxed public attitude regarding its potential harm, popularization by the media and by groups advocating legalization, the current trend of smoking marijuana-filled cigars known as "blunts," and the Internet. At the present time, scores of websites provide information and links extolling the virtues of marijuana. These sites provide forums for user group discussion, posting of documents and messages for public discussions, and advocate the legal sale of marijuana. Further, several websites advertise the sale of marijuana and provide instructions on home cultivation (14). Marijuana is a cash crop in many communities. Lynskey et al (4) reported that an association between early cannabis use and subsequent drug use and abuse/dependence arises from peer pressure and the social context in which cannabis is obtained and used. Approximately one-third of Americans support the legalization of marijuana (15). In addition, nearly $80 \%$ of the U.S. population approves of marijuana for medical purposes and believe that people using marijuana recreationally should not be fined or jailed (15). The general public considers marijuana to be associated with very low health risks (16).

Pharmacological evidence suggests that exposure to cannabis induces subtle biochemical changes that may encourage drug-taking behaviors (17). This hypothesis is based on similarities between the effects of marijuana and heroin on opioid receptors (18). It also has been shown that chronic exposure to marijuana induces cross-tolerance to opioids and amphetamines $(18,19)$. Other proposed mechanisms for increased marijuana use include initial experiences with marijuana, which are frequently rated as pleasurable and encourage continued use of marijuana and broader drug experimentation (20). Seemingly safe early experiences with marijuana may reduce the perceived risk of, and therefore barriers to, use of other drugs. This may provide individu- als with access to other drugs as they come in contact with drug dealers (21) or sellers of prescription-controlled substances. The National Household Survey on Drug Abuse (NHSDA) in 2001 (2) reported a significant decline in the perceived risk of marijuana coupled with an increased awareness of its easy availability.

Furthermore, isolated scientific publications colliding with ideas about drugfree environments, have shown cannabinoids to block pain response in laboratory pain models and in some patients with cancer or non-cancer pain (5-7). An endogenous cannabinoid system involved in pain modulation that produces analgesia through the same brain stem circuitry involved in opioid analgesia also has described $(5,8-10)$. This has led to the postulates that co-administration of a cannabinoid may lead to a lower opioid requirement $(11,12)$. Medical marijuana access program established in Canada (11-13) has not helped the campaign for drug free environment in the United States.

The National Household Survey on Drug Abuse (2) showed that the initiation of non-medical prescription type drug abuse has been increasing, since the mid-80s from about 400,000 new users to $2,000,000$, a five-fold increase over a period of 14 years. It was also shown that those who used prescription drugs nonmedically in the past year had a higher rate of other illicit drugs. Sixty-three percent of adolescents and young adults who used prescription drugs non-medically in the past year also used marijuana in the past year. In contrast, only $17 \%$ of adolescents and young adults who had not used prescription drugs non-medically in the past year had used marijuana.

Cocaine is the second most commonly used illicit drug in the United States. It is available as a white crystal, powder, or as crack or rock cocaine (22). Crack cocaine is usually smoked, whereas powdered cocaine is snorted or dissolved in water and injected. About 10\% of Americans over the age of 12 have tried cocaine in some form at least once, about $2 \%$ have tried crack, and nearly $1 \%$ of the population uses cocaine on a regular basis (22-24). Cocaine is a powerful, addictive drug (25), with severe associated medical complications, including chest pain, pulmonary trauma, and bleeding (26). Concomitant use of cocaine with alcohol increases the risk of accidental death (27).

Although there are extensive data on the use of illicit drugs in the general population, there are few data documenting use of illicit drugs in patients taking prescription controlled substances, such as analgesics. Consequently, there are no theories predicting that abuse of prescriptioncontrolled substances increases the rate of illicit drug use. This relationship has been noted with marijuana and controlled substance usage, but not vice versa. However, the same mechanisms may apply. For example, it has been shown that chronic treatment with THC induces cross-tolerance to opioids in rats. Additionally, perceptions about controlled substances may be similar to those of marijuana, where drug use is pleasurable and deemed to be safe, because the drugs are prescribed by physicians. Because of easy access, patients with chronic pain syndromes and associated psychological disorders, such as depression or anxiety, may be at risk of illicit drug abuse as well. Patients see physicians for treatment of chronic pain more than any other medical disorder. Further, patients taking prescription drugs for chronic pain may obtain illicit drugs for self-treatment purposes, including pain relief, to facilitate sleep, to improve appetite, and for pleasure. In the present study, there was a correlation between controlled substance abuse and illicit drug use. While it remains to be seen if prescription-controlled substance abuse functions as a gateway to illicit drug use, it is apparent that patients who abuse prescription medications have a higher rate of illicit drug use.

In addition to marijuana, cocaine remains a significant threat to patient health, with $4 \%$ of patients without concomitant prescription drug abuse using cocaine, and $12 \%$ of patients with prescription abuse using cocaine. This is in contrast to a $0.7 \%$ to $1 \%$ prevalence of cocaine use in the general population (2, 22-24).

Random drug testing may be performed in many ways. Rapid Drug Screen is performed easily and inexpensively. This test utilizes a competitive immunoassay technique for the simultaneous detection of multiple illicit substances. The test device consists of a membrane strip with an immobilized drug conjugate. Quality control is provided with the test. Qualitative detection thresholds for various drugs are: amphetamines 1,000 ng/ $\mathrm{mL}$, cocaine $300 \mathrm{ng} / \mathrm{mL}$, marijuana or cannabinoids $50 \mathrm{ng} / \mathrm{mL}$. These screening 
cut-off concentrations are recommended by the Substance Abuse Mental Health Services Administration (SAMHSA). For confirmation, a quantitative analytical method should be used. Further screening may use the DS-9 test (drug screen-9), which can be performed either by the enzyme-multiplied immunoassay technique (EMIT) or the fluorescent polarization immunoassay (FPIA).

Currently, physicians may choose not to obtain drug screens when patients adhere to a controlled substance agreement, have a clean report on doctor shopping, and do not obtain prescriptions outside the agreement. Such patients are considered not to have evidence of controlled substance abuse. For that reason, it would be expected that use of illicit drugs in this group would be absent or extremely low. However, this study challenges this assumption, because $14 \%$ of patients who did not appear to abuse prescription drugs used illicit drugs, and $34 \%$ of patients with evidence of prescription abuse used illicit drugs. These results are similar to our previous study (1).

Some have suggested that all patients undergo random urine drug testing for illicit drugs, irrespective of their prescription usage pattern (28-30). Based on the results of this study, this appears to be a reasonable course of action. However, this usually involves urine drug testing with tests such as the DS-9 test (drug screen-9), followed by OPGCMS (opiates by gas chromatography mass spectroscopy) for confirmation. Performing both tests is cumbersome, expensive, and, at times, impractical. The Rapid Drug Screen ${ }^{\mathrm{TM}}$ test, as utilized in this study, is inexpensive (around \$6-\$12 per test) and is easily performed in the physician's office.

Other questions raised by this study include potential consequences of identifying illicit drugs in patients who are receiving prescriptions for controlled substances, such as opioids. Each physician must establish a threshold level for his or her practice, and follow the policies appropriately. With marijuana, a key question is whether one may be somewhat lenient and give a patient several chances to abstain, as proven by subsequent random drug testing. With cocaine, the situation is different, and a zero-tolerance policy may be the established.

\section{Conclusion}

Based on this study, there appears to be a high rate of illicit drug use in an interventional pain management setting, with $34 \%$ of patients abusing prescription-controlled substances also using illicit drugs and $14 \%$ of patients without prescription drug abuse using illicit drugs. There was no evidence of amphetamine or methamphetamine use or combined use of marijuana and cocaine. Physicians must be vigilant and consider random testing of all patients on controlled substances for concomitant illicit drug use, including marijuana and cocaine.

\section{ACKNOWLEDGMENTS}

The authors wish to thank Tonie Hatton; Karla Hall, RN, BSN; Jennifer Martin, RN;Lisa Isbell, RN; Marla Neihoff; and Lori Caldwell for their assistance in completion of this study and preparation of this manuscript.

Author Affiliation:
Laxmaiah Manchikanti, MD
Medical Director
Pain Management Center of Paducah
2831 Lone Oak Road
Paducah, Kentucky 42003
E-mail: drm@apex.net

Kim S. Damron, $\mathrm{RN}$

Clinical Coordinator

Ambulatory Surgery Center

2831 Lone Oak Road,

Paducah, Kentucky 42003

E-mail: kim@painmd.com

\section{Carla D. Beyer, RN, BSN}

Clinical Coordinator

Ambulatory Surgery Center

2831 Lone Oak Road

Paducah, Kentucky 42003

E-mail: carla@thepainmd.com

\section{Vidyasagar Pampati, MSc}

Statistician

Pain Management Center of Paducah 2831 Lone Oak Road,

Paducah, Kentucky 42003

E-mail: sagar@painmd.com

\section{REFERENCES}

1. Manchikanti L, Pampati V, Damron K, Beyer C, Barnhill R. Prevalence of illicit drug use in patients without controlled substance abuse in interventional pain management. Pain Physician 2003; 6:173178 .

2. 2001 National Household Survey on Drug Abuse (NHSDA). DHHS Publication No. (SMA) 02-3758. Rockville, MD: Department of Health and Human Services; Substance Abuse and Mental Health Services Administration, 2002.

3. Sloboda Z. Drug abuse patterns in the United States. IEWG June 1999; 89-107.

4. Lynskey MT, Heath AC, Bucholz KK et al. Escalation of drug use in early-onset cannabis users vs co-twin controls. JAMA 2003; 289: 427-433.

5. Walker MJ, Strangman NM, Huang SM. Cannabinoids and pain. Pain Res Manage 2001; 6:74-79.

6. Tsou K, Lowitz KA, Hohmann AG et al. Suppression of noxious stimulus-evoked expression of Foslike immunoreactivity in rat spinal cord by a selective cannabinoid ag onist. Neuroscience 1995; 70:791-798.

7. Herzberg U, Eliav E, Bennett GJ et al. The analgesic effects of $R(+)$-WIN 55,212-2 mesylate, a high affinity cannabinoid agonist, in a rat model of neuropathic pain. Neurosci Lett 1997; 221:157-160.

8. Martin WJ. Basic mechanisms of cannabinoid-induced analgesia. IASP Newsletter, Summer, 1999:3-6.

9. Richardson JD. Cannabinoids modulate pain by multiple mechanisms of action. J Pain 2000; 1:2-14.

10. Meng ID, Manning BH, Martin WJ et al. An analgesia circuit activated by cannabinoids. Nature 1998; 395:381-383.

11. Holdcroft A, Smith M, Jacklin A et al. Pain relief with oral cannabinoids in familial Mediterranean fever. Anesthesia 1997; 52:483-488.

12. Lynch ME, Clark AJ. Cannabis reduces opioid dose in the treatment of chronic noncancer pain. J Pain Symptom Manage 2003 25:496-498.

13. Ohlsson A, Lindgren JE, Whalen A et al. Plasma delta-9-tetrahydrocannabinol concentrations and clinical effects after oral and intravenous administration and smoking. Clin Pharmacol Ther 1980; 28:409416.

14. Drug trafficking in the United States. Available at: http://www.usdoj.gov/dea/ concern/drug_trafficking.html.

15. Stein J. The new politics of pot. TIME; Nov 4, 2002; 56-61.

16. Cloud J. Is pot good for you? TIME, Nov 4 2002; 62-66.

17. Nahas G. Keep Off the Grass. Middlebury, Vt: Paul Eriksson: 1990.

18. Lamarque S, Taghouzti K, Simon H. Chronic treatment with $\mathrm{D}$-tetrahydrocannabinol enhances the locomotor response to am- 
phetamine and heroin: Implications for vulnerability to drug addiction. Neuropharmacology 2001; 41:118-129.

19. Cadoni C, Pisanu A, Solinas M et al. Behavioural sensitization after repeated exposure to D9-tetrahydrocannabinol and cross-sensitization with morphine. Psychopharmacology 2001; 158:259-266.

20. Fergusson DM, Lynskey MT, Horwood LJ. Patterns of cannabis use among 13-14 year old New Zealanders. N Z Med / 1993; 106:247-250.

21. Cohen H. Multiple drug use considered in the light of the stepping-stone hypothesis. Int J Addict 1972; 7:27-55.
22. National Institute on Drug Abuse, Infofax: Crack and Cocaine, October 2001.

23. Drug Enforcement Administration, Drug Descriptions: Cocaine.

24. Substance Abuse and Mental Health Services Administration, Summary of Findings from 2000 National Household Survey on Drug Abuse, September 2001.

25. Office of National Drug Control Policy, Drug Facts: Cocaine, May 2002.

26. National Institute on Drug Abuse, Infofax: Crack and Cocaine, October 2001.

27. Office of National Drug Control Policy, Drug Facts: Cocaine, May 2002.
28. Atluri S, Sudarshan G. A screening tool to determine the risk of prescription opioid abuse among patients with chronic nonmalignant pain. Pain Physician 2002; 5 : 447-448.

29. Kentucky Board of Medical Licensure. Model guidelines for the use of controlled substances in pain treatment. J Ky Med Assoc 2001; 99:291-2944.

30. Manchikanti L, Brown K, Singh V. National All Schedules Prescription Electronic Reporting Act (NASPER): Balancing substance abuse and medical necessity. Pain Physician 2002; 5:294-319. 
